\title{
The Importance of the Financial Derivatives Markets to Economic Development in the World's Four Major Economies
}

\author{
${ }^{1}$ A. Sarveswara Reddy, ${ }^{2}$ K.Sathish \\ ${ }^{1,2}$ Assistant Professor, Department of Science \& Humanities, St. Martin's Engineering College, \\ Telangana, India. ${ }^{1}$ sarveswarareddysh@smec.ac.in, ${ }^{2}$ ksathish.mgt@smec.ac.in
}

Abstract During the past 30 years, India and China have achieved economic power in adjacent proximity towards Japan along with also the U.S. Throughout the particular phase, the value of the derivatives industry in the economic sector continues to be commonly recognized. Nevertheless, small supporting research can be purchased on the economic consequences of is. This particular paper investigates the powerful association between the derivatives marketplaces as well as economic improvement of these 4 big economies that we think about in concert so the CIJU (China, India, Japan and the U.S.) team. We make the utilization of a Granger connection check in the framework of the vector error correction model (VECM) to look at given dynamic as well as causal association with details for the duration $1998 Q 1$ to 2017Q4. Imitative marketplaces are actually discovered to favorably add to financial improvement in the very small time in India, Japan, and the U.S., though the outcome fades in the extensive haul. In China, the products market place leads to a damaging outcome on economic improvement in the very small run. Nevertheless, as per the long term, we view a good impact as of the byproducts industry on economic growth built mostly over two long term opinion strategies, specifically, powerful standard very least squares and completely altered regular least squares. Furthermore, the improvement of derivative market segments brings about development volatility in India, each in the very small run along with very long term.

Keywords - Economic development; Derivatives market; Vector error correction model (VECM); Granger-causality tests; DOLS; FMOLS

\section{INTRODUCTION}

The improvement of the byproducts market has extended been a subject of attention with scientists, makers of policy, as well as monetary interventions. This conventionally shows a crucial role of it in the monetary system as well as significantly gives to different facets of an economic climate like an entire. Zhang and lien (2008) summarize the roles as well as features of the byproducts market place in developing economies, in each empirical and theoretical scientific study. For starters, the derivatives market place provides a good mechanism which eases the cost of sharing chances aimed at supplies operated on the sector; assisting makers cope with cost volatility. In addition, it can serve as a vital purpose of sleek hedging as well as risk management by improving capital inflows in appearing as well as developing nations, though it's a destructive influence on economic devices by introducing a lot more unforeseen problems characteristics and it is a contagion's driver. Next, it's commonly recognized that the byproducts market operates as a risk reduction channel in addition to relocation, a resource of cost along with cost finding additive. Different derived devices seem to match the danger choice of various agents, like spectaculars or perhaps hedgers. The byproducts market place is actually likely to improve information passes on the market. Data about succeeding costs is a lot more apt to mirror upcoming need, therefore influencing generation as well as storage space choices and ultimately lowering area volatility of price. As provided by Atilgan et al. (2016) an updated literature survey on byproducts in appearing nations, isolating empirical scientific analysis into organizations based on the performance of the byproducts current market. Apart from apprising the performance of the byproducts industry on evading as well as management of risk in addition to cost finding in the area sector, they investigate problems concerning promote framework as well as productivity, and also danger as well as cost extent.

By the derivatives market place an essential role was played in the economic system is actually essential by means of a 
great quantity of investigation have been carried out, each empirically and theoretically. Nevertheless, a controversy over the influences of the economic growth of it has risen due to a shortage of secondary confirmation. To as a superlative of the consent of ours, couple of theoretical scientific studies point out the effect of the improvement of the derivatives industry on economic progress (Sammer and Haiss 2010). A few contemporary scientific analyses demonstrate a link amid the economic progress along with danger, ultimately inferring derivatives current market's primary roles. Zilibotti and Acemoglu (1997) suggest a unit where regular agent consequences impact economic progress and aggregate volatility with the funding relocation; elements seem to capitalize in tasks of higher return that seem to require much improved variation potentials. Krebs (2003) discloses that the idiosyncratic hazard removal results in an actual physical ratio decline to a growth and human resources of the amount of investment return shipping as well as welfare. To sum up, possessing innovative monetary resources fosters a much better division of online resources, each financial and human, to far more effective tasks, therefore improving economic development.

Our study examines the vibrant association with the improvement of byproducts marketplaces, economic progress, instability, along with other macro-economic attributes, specifically; openness of trade as well as rates of interest. As if think about the world's four huge economies by big derivatives marketplaces - The U.S., Japan, India, and China - that we think about mutually "as the CIJU places. The U.S. is definitely the largest economic climate with a genuine uncivilized domestic product (GDP) of approximately $\$ 17$ trillion. China has" encountered outstanding development in the real GDP of it's during the last 20 years, today approximately $\$ 8.5$ billion, creating it as the world's additional major economic climate. Though its actual GDP presently has probably the slowest boost, Japan is nevertheless 1 of the biggest economies, by genuine GDP of about 6 dolars trillion. Genuine GDP of India has grown much more as of the threefold as per the given particular period (about " $\$ 2.5$ trillion). The progress in actual GDP is actually convoyed by a growth in GDP for every capita in the places (see Table 1)."

Table 1. Real GDP and real GDP per capita in selected countries.

\begin{tabular}{lcccccc}
\hline \multirow{2}{*}{ Country } & \multicolumn{3}{c}{ Real GDP (5 Billion) } & \multicolumn{3}{c}{ Real GDP per Capita (5) } \\
\cline { 2 - 7 } & 1996 & 2007 & 2016 & 1998 & 2007 & 2016 \\
\hline China & 1915 & 4596 & 8506 & 1542 & 3458 & 6894 \\
India & 710 & 1333 & 2466 & 699 & 1130 & 1862 \\
Japan & 5217 & 5848 & 6053 & 41,277 & 45,687 & 47,661 \\
USA & 11,667 & 15,065 & 16,920 & 42,293 & 49,979 & 52319
\end{tabular}

Source: (World Bank. n.d. n.d.)
Our analysis plays a role in the literature by means of concentrating proceeding the CIJU nations, that must had older byproducts marketplaces evaluating the short as well as long run consequences of the byproducts sector, the openness of the trade, along with the interest rate over economic growth and economic expansion volatility by using a number of time-series econometric strategies which present an analytical strategy that's suitable for the readily available information, as well as dealing with possible endogeneity issues in the deterioration.

The setoff the paper is actually set as studies. Observing the Overview, Section two critiques the appropriate literature in phrases of empirical and theoretical scientific studies. Area three provides an introduction of the derivatives market place in the CIJU places. Next, we use different econometric methods to look at the dynamics of cointegration as well as stationarity of the information in Section 4 . Then, the information is presented by us and talk about the empirical outcomes of ours in Section 5. Last but not least, we existing concluding remarks as well as policy ramifications in Section 6.

\section{LiterATURE REVIEW}

A decent contract of hard work has been growing in checking out the key impact of the improvement of the byproducts industry on numerous factors of economic methods. Sammer and haiss (2010) check out the job of byproducts of the nexus amid development as well as financial by three channels: risk, competence, along with volume. For starters, in the volume station, the improvement of byproducts marketplaces affects the economic market place as well as economic progress by facilitating as well as raising the buildup of capital. It improves the allocation of materials in expense tasks from greater fees of arrival with the aid of the cost savings mobility as well as the greater possibility of buy in a huge assortment of unsafe jobs. Next, the effectiveness channel is actually a summary of several features, like an effective replacement for money marketplace trade, source action throughout room and time, along with an information provider for risk control as well as cost technique. It's thus good for this kind of elements as companies, financial institutions, as well as the federal government to obligate a bigger mixture of the sources of funding at reduced expenses. 3rd, the channel with danger is actually worried about the destructive influence of byproducts market improvement over the economic market place as well as economic development. It might increase speculation regarding root resources, building the fiscal markets much extra instable along with putting in a lot more anxiety to the economic climate. Nevertheless, utilizing byproducts as hedging tools might be helpful for elements along with firms (see e.g., Ofek and Allayannis 2001; Bartram et al. 2009; McAleer and Hammoudeh 2013; Huang et al. 2017; Dempsey and Tanha 2017). 
Sendeniz-Yüncü et al. (2018) note that a derivatives market of well-functioning" varieties it easy for organizations to discuss chances effectively and provide permits to carry out tasks by means of greater hazard and thus to increase economic development. At exactly the same period, elements, like investors, customers, and creators, could depend over the byproducts industry as a channel of information which mirrors balance costs to ensure that they are able to make the proper conclusions, cultivating the effectiveness of source division and accordingly causing in economic development.

The underlying association amid the commodities industry as well as economic progress in each created as well as emerging countries is actually emphasized in $S_{\text {s }}$ endenizYüncü et al. (2018)'s analysis built on the information of time series. It was discovered by then that, 29 from 32 countries around the world learned, the two attributes of matter have a long term connection where the nations of middle income require a Granger connection impact after the commodities market to financial development although in the places of high income the influence is actually turned around. Given experts differentiate these exact conflicting one-directional actions involving growth of futures market as well as economic development. As per the other side, the path begins as per the futures market growth to fiscal development in many nations by fairly small genuine GDP per capita. As per the flip side, of lands with a somewhat steep genuine per capita GDP, economic progress has a tendency to result in the futures market improvement. Similar to Khan et al. (2017) working with a panel route autoregressive procedure as well as also the strategy of Granger causality, Vo et al. (2019) clearly display the presence of one-direction Granger interconnection involving the byproducts industry and fiscal progress, though the causal association diverges amid middleincome and high- nations.

The empirical trainings concentrate on the associations amid economic progress as well as economic sector growth, instead of the derivatives current market. Different studies have approached economic progress through the improvement of fiscal intermediaries, like banking industry growth "(Beck et al. 2000; Levine and King 1993; Levine et al. 2000; Levine 2005; Menyah et al. 2014; Pradhan et al. 2014; Chaiechi 2012), stock market growth (Tsouma 2009; McKibbin and Ang 2007; Huang et al. 2000), and bond market development (Cos $\mathrm{s}$ kun et al. 2017; Thumrongvit et al. 2013).1 Pradhan et al. (2014)" carry out an evaluation on balancing associations with 4 economic components - which includes the banking sector, stocks, and economic progress - as well as macro variables, for example international strong buy (FDI), inflation rate, trade openness, along with the usage of federal government as well as the spending. Of given sorted attributes, the economic industry, banking, as well as the derivatives industry are actually discovered to increase fiscal progress, while the macro attributes, specifically FDI as well as openness of the trade, appear to outgrow the fiscal events with the standard market as well as the channel of banking.

Empirical as well as theoretical studies have conferred about the macroeconomic variables job in association amid monetary evolution along with the economic progress or maybe the capital sector that clearly incorporates the derivatives current market. The utilization of macro-economic factors might be sometimes divided (Kim et al. 2010) or even concurrent (Cos,kun et al. 2017; Gries et al. 2009; Menyah et al. 2014; Pradhan et al. 2014; Wachtel and Rousseau 2002). Kim et al. (2010) talked about how openness of the" trade effects the improvement of fiscal industry while Menyah et al.

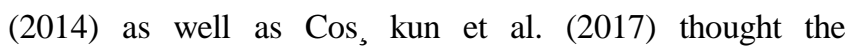
interweave in amid fiscal growth, openness of trade, along with economic development. Additionally, Pradhan et al. (2014) disclosed that a blend amid an older financial industry along with a macroeconomic strategy of having inflation level underneath management will lead to a greater rate of growth depending over a big illustration of Asian countries in excess of last 4 years. Thumrongvit et al. (2013 Ruiz and) (2018) also wear variations of macroeconomic aspects as command variables of the exploration the consequences of fiscal improvement on economic development. Malik as well as Bowdler (2017) look for a statically considerable impact of the openness of trade over increasing instability.

\section{1. "OVERVIEW ON THE DERIVATIVES MARKET IN THE CIJU"}

An item which is derivative could easily be described as a monetary tool whose assessment will depend over or perhaps is actually produced after, the valuation of a fundamental adjustable, and this may be dealt within derivative market segments, operated sometimes on the interchange or perhaps with the stand (OTC). The root adjustable usually mentions toward the price tag of traded resources. The market of derivatives place has been effective since not merely has which involved a lot of kinds of elements as of speculators \& hedgers to arbitrageurs, though it's additionally brought a good liquidity offer. The market place of derivatives is usually split into two sets that are little: monetary derivatives and commodity that contain various instruments, each complex and simple. The 4 easy instruments are forwards, futures, choices, as well as trades, while the more complicated people incorporate the ones known as amazing and recognition derivatives, and also water, power, and insurance derivatives. Information on the application as well as the roles of the instruments are actually talked about in Hull (2005 Sundaram and) (2012).

Two vital parts of the derivatives industry are actually choices as well as futures that are commonly traded almost all across the globe. They're split into 10 organizations such as agriculture, metals which are non-precious, valuable metals, currency, energy, rate of interest, impartiality as individual, and index of equity. Figure 1 represents the 
volume trading with the previous years in the exchanged traded sector, displaying a growth in the capacity of the derivatives traded sorts following the worldwide financial problem, out of about 17.5 billion in 2008 to the good of it's of twenty five billion in 2011. More than the following 3 years after the peak of it in 2011, the volume of trade exchange prospects as well as alternatives fallen significantly, prior to recovering to the maximum amount of its of 2015. A growth in the traded measurements following the problems might indicate that corporates or maybe elements have left revolved addicted to derivative tools for the hedging requirements of their.

Involving the CIJU nations, Japan and also the U.S. have probably the furthermost extended upright derivatives marketplaces, by the set up of very principal futures exchange in the Dojima Rice Exchange in Osaka, Japan, in 1730. The Board of Trade in Chicago was established in the U.S. in 1848 (Sundaram 2012). In comparison, the market place of derivatives of China started lately, by means of the China Financial Futures Exchange inaugural in Shanghai in September 2006 and far along an OTC industry of derivatives known as the Shanghai Clearing House in November 2009. Nevertheless, based on a topical introduction of China's derivatives trade by Zhou (2016), the land has world's one of the biggest service markets built over trade quantity and its growing rate. CSRC (China Securities Regulatory Commission) found that commodity sector trading of China, for five years antiquated at levels of the world; by way of the volume of the snowball long term sector was about $\$ 2.5$ billion along with the turnover as cumulatively of it was roughly $\$ 292$ trillion. As, the country's derivatives market place in India has appeared as well as cultivated recently by a drastically great utilization of derivatives tools. The trend of liberalization and globalization in various planet's regions completed risk control much additionally critical than in the past (Kumar and Vashishtha 2010). This particular perspective is actually sustained through a remarkable rise in the OTC day turnover, for the devices of both foreign exchange as well as rate of interest derivatives marketplaces, as suggested in Table 2.

${ }^{1}$ Ang (2008) conducts a thorough survey of the literature in relation to the development of finance and growth.

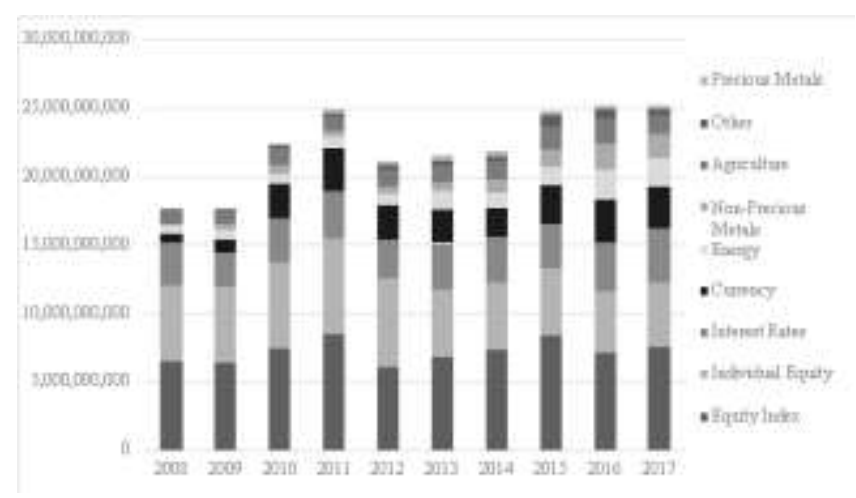

Figure 1. Annual volume of exchange-traded futures and options by category. Source: (Future Industry Association. n.d. n.d.).

Table 2. The daily average OTC turnover.

\begin{tabular}{|c|c|c|c|c|c|c|}
\hline \multirow[t]{2}{*}{ Country } & \multicolumn{3}{|c|}{ Foreign Exchange Instruments } & \multicolumn{3}{|c|}{ Interest Rate Derivatives } \\
\hline & 1948 & 20007 & 2016 & 1998 & 2007 & 2016 \\
\hline Crint & 211 & 9255 & 72833 & & & 4050 \\
\hline India & 2445 & 38,365 & 4.330 & & 3395 & 1858 \\
\hline Japaea & 146.268 & 280.223 & 399,028 & 31,627 & 76,367 & 55910 \\
\hline United States & 363,388 & 745,202 & 1,202122 & 58,447 & 525,011 & $1,240,774$ \\
\hline
\end{tabular}

Source: (Bank for International Settlements (BIS)).

\section{Methodology}

We deal with the derivatives industry effect over fiscal progress as well as development volatility in 4 economies with evaluation of time series in the long as well as the short run. For starters, the effect of short run was viewed through the Impulse Response Function (IRFs) by way of possibly a Vector Error Correction Model (VECM), in case an extended connection is existent, or maybe a Vector Autoregressor (VAR) designs. The appearance of integration connection made it possible for us to mark the long term result with Dynamic Ordinary Least Squares (DOLS) along with Fully Modified Ordinary Least Squares (FMOLS), consequently we probably takes the issue of endogeneity into consideration. Next, we retrieved the fundamental connection amid the sector of derivatives, macroeconomic attributes, along with the economic progress, in addition to progress volatility with the application of a causality examination. Last but not least, based mostly on the outcomes of ours, we provide policy ramifications for nations on the road of advertising the derivatives market of theirs, particularly in appearing as well as building places with underdeveloped monetary methods.

\subsection{Model Specification}

According to the considerable review of ours of the literature on economic growth and fiscal growth and empirical scientific analysis on given association, an analytical framework have been constructed by us comprising of the derivatives sector, fiscal progress, along with 2 macro-economic elements, the rate of interest as well as openness of trade, that serve as command attributes. The original objective of ours was developing an appropriate process for the relation approximation amid the attributes. The specification of regression is actually given as

$$
\operatorname{LnGDPR}_{t}^{i}=\alpha_{0}+\alpha_{1} \operatorname{LnDERR}_{t}^{i}+\alpha_{2} \operatorname{INTR}_{t}^{i}+\alpha_{3} \operatorname{LnOPEN}_{t}^{i}+\varepsilon_{t}^{i}
$$

where $i$ and $t$ signify the sample country $(i=1, \ldots, 4)$ along with the time series, correspondingly. GDPR ${ }^{i}$ at time $\mathrm{t}$ in country $\mathrm{i}$ is the open gross domestic product $\left(\mathrm{GDP}^{\mathrm{t}}\right)$, as well as DERR ${ }^{i}$ is actually the actual worth of derivatives 
tradeoff of argument fee industry. The nominal values of GDP as well as derivatives trading are actually changed into real words working with the consumer cost index (CPI). $I_{N T R}{ }^{i}$ is actually the actual interest rate that is actually estimated by deducting the interest rate as nominal from the inflation rate. $O P E N^{i}$ is definitely the complete exports ratio as well as importations to GDP. In conclusion, $\varepsilon_{i t}$ is actually the errors expression, along with the logarithm is denoted by Ln.

A regarding problem would be that the substantial improvement of derivatives is actually related with increased instability in economic progress as it might boost higher indecision of the economic climate. In direction to tackle with the difficulty, we integrated the derivatives sector, progress instability, along with two macro-economic elements, the rate of interest as well as openness of the trade into an incorporated context in that the development volatility (VOL) got the economic development job as the reliant adjustable in Equation (1). Put simply, we consequent to the projected equation as follow:

$$
\text { VOL }_{t}^{i}=\alpha_{0}+\alpha_{1} \operatorname{LnDERR}_{t}^{i}+\alpha_{2} \operatorname{INTR}_{t}^{i}+\alpha_{3} \operatorname{LnOPEN}_{t}^{i}+\varepsilon_{t}^{i}
$$

Wherever $V O L_{t}^{i}$ is actually the volatility of genuine progress rate of lands $i$ at year t, assessed through the conventional deviation rate of growth of 4 prior lodgings.

The analysis enclosed the 4 leading economies of the planet, specifically, China, India, Japan, and the United States. The diverse of timeframe throughout nations, beginning in 2006Q3 for China, 2007Q2 for India, as well as 1998Q1 for Japan as well as also the U.S. Details to the evaluation had been gathered from different resources. Advice on the market of derivatives initiates in the Bank for International Settlements (BIS) repository. It's tough to explain a great degree for the sector of derivatives that attains a range of things. With this paper, we proxy it through complete eccentric exchange operated derivatives notation quantities. ${ }^{2}$ As per the variables of staying, we found information as of the International Financial Statistics (IFS), International Monetary Fund (IMF). Table 3 defines the variables data.

${ }^{2} \mathrm{We}$ assumed that the currency used for trading derivatives is that of the country formally issuing it. The total outstanding notation amounts of exchange-traded derivatives in terms of U.S. dollars are listed for the U.S. and the other countries in the sample.
Table 3. Data description.

\begin{tabular}{cccccc}
\hline Varriable & Obs. & Mean & Std. Dev. & Min & Max \\
\hline \multicolumn{5}{c}{ China } \\
\hline LnGDPR & 46 & 14.36 & 0.36 & 13.60 & 14.90 \\
VOL & 41 & 0.44 & 0.28 & 0.09 & 1.25 \\
LDDERR & 46 & 1.74 & 223 & $(1.68)$ & 5.38 \\
INRT & 46 & 5.46 & 124 & 3.63 & 7.91 \\
LnOPEN & 46 & 3.79 & 0.21 & 3.47 & 4.22
\end{tabular}

Table 3. Cont.

\begin{tabular}{|c|c|c|c|c|c|}
\hline Variable & Ohe & Mean & Std. Des. & Min & Max \\
\hline \multicolumn{6}{|c|}{ India } \\
\hline LIGDPR & 42 & 12.87 & 0.00 & 1274 & 1306 \\
\hline VOL & 38 & 0.59 & 0.57 & 0.07 & 1.97 \\
\hline LHDERR & 43 & 2.03 & 2.80 & (4.41) & 4.50 \\
\hline INRT & 43 & 0.86 & 3,92 & 5.75 & $15 . \pi$ \\
\hline LIOPEN & 42 & 3.55 & 0.16 & 3.29 & 381 \\
\hline \multicolumn{6}{|c|}{ Iapan } \\
\hline LIGDPR & 78 & 13.99 & 0.13 & 13.70 & 1433 \\
\hline VOL & 75 & 0.12 & 0.05 & 0.02 & 0.23 \\
\hline LnDERR & 80 & 9.18 & 0.73 & 7.82 & 10.41 \\
\hline INRT & 77 & 1.65 & 0.34 & 0.96 & 229 \\
\hline LIOPEN & 78 & 3.15 & 0.23 & 2.65 & 3.56 \\
\hline \multicolumn{6}{|c|}{ Uinited States } \\
\hline LIGDPR & 80 & 15.11 & 0.10 & 14.91 & 15.29 \\
\hline WOL & 75 & 0.11 & 0.04 & 0.01 & 022 \\
\hline LHDERR & 80 & 12.49 & 0.59 & 11.18 & 1322 \\
\hline INRT & 78 & 5.81 & 3,02 & 2.97 & 1197 \\
\hline LIOPEN & 80 & 3.0. & 0.11 & 2.78 & 3.22 \\
\hline
\end{tabular}

\subsection{Unit-Root Tests}

To take a look at the way the improvement in sector of derivatives, particularly the exchange fees trading, impacts economic development over long and short run, Equations were assessed by (1) and (2) Equations for every single nation. Utilizing strategies of time succession, we started by tests if the attributes were constant as well as whether they'd a co-integrated connection. For starters, to think about the stationarity, we implemented the Dickey Fuller comprehensive very least squares (DFGLS) unit root check suggested by Elliott et al. (1996). The DFGLS check is actually apparent to produce much improved outcomes by a little trial as well as has considerably higher energy as opposed to the augmented DF prior variant with start testing. The sequence of time have been converted through a general minimum squares (GLS) regression prior to the assessment has been achieved. Furthermore, with the very long time of approximately eighty quarters, the information sequence might display structural pauses because of to, for instance, the dotcom crash as well as the 2008 worldwide fiscal problem. We additionally functional to the unit root of ZA check by Andrews and Zivot (1992), and that requires the structural shifts presence in the sequence into consideration. 


\subsection{Cointegration Test}

The subsequent thing is examining the long run connection with 4 selected variables. The analysis engages the bound assessment way to co-integration by Pesaran et al. (2001).3 2 suggested examinations, regular F- as well as $\mathrm{t}$ statistics, had been carried out on the provisional mistake foundation modification method with the autoregressive sent out lag (ARDL) design. Equations (1) and (2) is actually conveyed in phrases of errors modification edition of the ARDL design as given below:

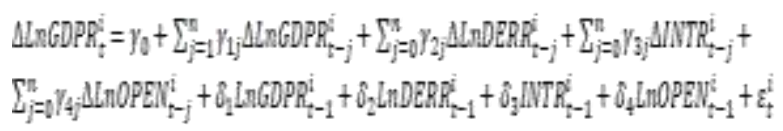

(3)

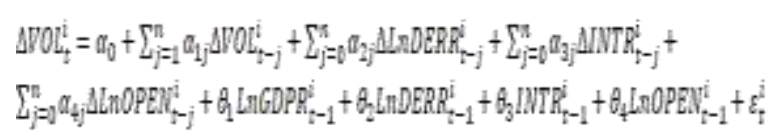

(4)

where $\Delta$ signifies the initial variance of a variable.

The bound examination co-integration consisted of 2 measures. For starters, the reliant variable was retreated on a regressors pair with the ARDL design making use of the Ordinary Least Square (OLS) method. Earlier to the bound check was used under following action; the mistake phrase must be proven to make certain it was homoskedastic and uncorrelated serially. The next action was confirming the existence of co-integration through locating whether each of the assessed lag amount coefficients corresponded as 0 with the F- as well as t statistics.

That's, the $t$ statistics tried the null theory $\delta_{1}=0$ from the alternative.

\subsection{Granger-Causality Test}

Equations (1) and (2) might display a causal association amid the dependent as well as independent variables. A comparable equation might be suggested, with every present impartial adjustable interim as a centered adjustable in turn. Consequently, we engaged a causality examination to simplify the variables path concerned. Deprived of the long run existent association with the Equations (1) and (2) variables, we carried out the standard causation check suggested through Granger and Engle (1987) on the VAR design.

To check out the uni and single directional causal link somewhere amid economic progress, progress volatility, as well as derivatives market improvement in perspective of appearance of a long run connection, we portrayed the Granger causality check with a VECM agenda in the subsequent equation:

$\Delta Z_{t}=\pi Z_{t-1}+\Gamma_{1} \Delta Z_{t-1}+\Gamma_{2} \Delta Z_{t-2}+\cdots+\Gamma_{p-1} \Delta Z_{t-p+1}+\varepsilon_{t} \ldots \ldots(5)$

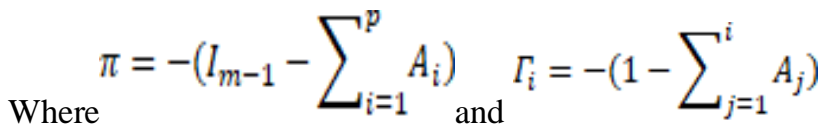

for $i=1, \ldots, p-1$. The matrix $\Pi\left(=\alpha \beta^{t}\right)$ involves together the speed of feature to the equilibrium $(\alpha)$ as well as long-run information $(\beta)$.

For checking out the causal connection amid economic progress as well as derivatives marketplaces grounded on Equation (one), the vector $\mathrm{Z}$ comprises of $\Delta \mathrm{Z}_{\mathrm{t}}=$ [ $\triangle \mathrm{LnGDPR}, \Delta \mathrm{LnDERR}, \Delta \mathrm{INTR}, \Delta \mathrm{LnOPEN}]^{\mathrm{I}}$, along with aimed at the situation of development volatility built on Equation (two), the vector $\mathrm{Z}$ includes of $\Delta \mathrm{Z}_{\mathrm{t}}=[\Delta \mathrm{VOL}$, $\triangle$ LnDERR, $\Delta$ INTR, $\Delta$ LnOPEN $]^{\mathrm{I}}$.

The assessment for causality of Granger was depending over the null theory that the coefficients ( $\Gamma \mathrm{i})$ on the independent variable's lagged standards weren't statistically distinct since zero concurrently, utilizing F statistics (Wald test). In rejection situations of the null hypothesis, a realization remained that the impartial adjustable did lead to the reliant adjustable, along with the dependent and independent variables disbursed a steady connection in the long term.

\section{EMPIRICAL RESULTS}

\subsection{Unit Root Tests and Cointegration Tests}

In order to figure out the alliance among the improvement of a by-product sector, monetary progress, as well as macroeconomic parameters in the short and long-run, we 1st examined the staticity of most of the parameters. The innovative DFGLS check by Elliott et al. (1996) as well as the ZA check by Andrews along with Zivot (1992) are actually carried out as well as provided in Table 4. The DFGLS disclosed that a few variables had been static like the interest rate of China as well as business acceptance in the United States while others involved device origins. In the act of DFGLS check, the majority of variables in these 4 countries around the globe had been detected to have device connections prepared on the ZA test.4 Seven out of eight product root analyses established the adjustable of progress volatility to be static at a minimum of 10 percent accepted

${ }^{3}$ The choice of a bound testing approach to cointegration has advantages. Not only does it do well in a small sample like ours, but it also ignores the problem of testing the longrun relationship between a dependent variable and a set of regressors irrespective of whether the regressors are $\mathrm{I}(0)$ or I(1). For more details on its advantages and application (see e.g., Pesaran et al. 2001; Narayan and Smyth 2005; Nguyen and Vo 2019).

amount. As a result, a realization found out a few had been built-in $\mathrm{I}(0)$, and nearly all series were $\mathrm{I}(1)$, based over the kind of staticity check. This particular attribute is very regular for macroeconomic parameters. 
Table A. Results of unit-root tests.

\begin{tabular}{|c|c|c|c|c|}
\hline & China & India & Japan & United States \\
\hline \multicolumn{5}{|c|}{ DFGL $5^{\circ}$} \\
\hline LUGDPR & -1.68 & -224 & -1.59 & -1.25 \\
\hline VOL & .269 & $.291^{*}$ & $-3.66 \ldots$ & -2.97 \\
\hline LADERR & -1.54 & -1.47 & -1.37 & -1.33 \\
\hline INIR & $-2.90^{\circ}$ & -1.16 & -1.9 & $-2.84^{*}$ \\
\hline InOPEN & .253 & -1.37 & -2.37 & .2 .91 . \\
\hline \multicolumn{5}{|c|}{$Z A$} \\
\hline \multirow{2}{*}{$\begin{array}{c}\text { LaGDPR } \\
\text { int }\end{array}$} & .428 & $-3,3$ & -4.07 & $-5.17 \%$ \\
\hline & $-469^{\circ}$ & $-5.70 \cdots$ & -4.67 & $-4.83 *$ \\
\hline LADERR & -3.82 & $-10,40^{\cdots 4}$ & -3.89 & $-3,37$ \\
\hline NTR & -3.58 & -3.41 & -5.19 & .3 .67 \\
\hline LIOPEN & -3.92 & -4.11 & -3.93 & .3 .72 \\
\hline
\end{tabular}

Notes: $* * *, * *$, and $*$ denote significance at the level of $1 \%$, $5 \%$, and $10 \%$, respectively. For the Elliott et al. (1996) DFGLS test, critical values for $1 \%, 5 \%$, and $10 \%$ were $-3.58,-3.03$, and -2.74 , respectively. For Zivot and Andrews

(1992) ZA test, critical values for $1 \%, 5 \%$, and $10 \%$ were $-5.34,-4.80$, and -4.58 , respectively.

To think about if the far run association continued with prefered variables of every land, we carried out 2 kinds of co-integration assessments: the ARDL bounds assessments by Pesaran et al. (2001), and the GH check by Hansen and Gregory (1996) to check out the susceptibility of the realization.

Outcomes resulted from co-integration assessments shown in Table 5. Situation (3) with the actual GDP becoming the reliant variable is actually found in Panel some time the situation of volatility of development in Equation (4) is actually provided in Panel B. From Panel A, based on the figured out $\mathrm{F}$ statistics \& $\mathrm{t}$ statistics, it'd a higher probability of declining the null hypothesis of absolutely no co-integration within the one percent acceptable amount in China. As per the F statistics, Japan rejected the the null theory, but the found particular realization wasn't supported by the $t$ statistics. In the 2 staying nations (United and India States), without research declined the null at also the $10 \%$ significance amount. The GH assessments came out to allow for the results from the ARDL bounds examinations, adding extra information on every nation's structural breaking. Much more precisely, a structural pause was in China and also the United States in 2008, as well as in Japan and India in 2011 as well as 2013, respectively. According to the co-integration examinations, we as a result arrived to the realization which revealed a far run connection with variables were around in China, however, not in the United States, Japan along with India. As far as the progress volatility is concerned, Panel B of Table 5 depicts failure of both the bound check as well as $\mathrm{GH}$ examination in refusal of the null hypothesis of absolutely no co-integration for the situation of the United States, Japan along with China, whereas India encountered the long haul connection with the hike volatility, derivatives sector, business acceptance, along with curiosity rate. ${ }^{5}$

Table 5. Results of Cointegation tects

\begin{tabular}{|c|c|c|c|c|}
\hline & China & India & lapan & $\begin{array}{l}\text { Lnited } \\
\text { States" }\end{array}$ \\
\hline \multicolumn{5}{|l|}{ Ponel $A$} \\
\hline & & Bound test & & \\
\hline F-statistics & $13,32 \mathrm{wn}$ & 282 & $6.73 \cdots$ & 1.43 \\
\hline t-statistics & $-5.24 \cdots$ & -147 & .277 & -1.86 \\
\hline $\begin{array}{l}\text { 2-statistics } \\
\text { Period break }\end{array}$ & $-784^{\cdots}$ & -4.76 & -4.42 & $\begin{array}{l}-5,50^{\circ} \\
20080^{3}\end{array}$ \\
\hline \multicolumn{5}{|l|}{ Ponsil B } \\
\hline F-statisticy & -241 & Bound test & 4.44 & $2 \theta 9$ \\
\hline \multirow[t]{2}{*}{ f-statistics } & +151 & $-5,38 \cdots$ & -3.94 & -3.27 \\
\hline & & $\begin{array}{c}-207 \\
G \text { test }\end{array}$ & & \\
\hline 2-statisbicg & -5.16 & $-6.04 *$ & -550 & -4.89 \\
\hline Feriad break & & & & $2001 Q 2$ \\
\hline
\end{tabular}

Notes: ***, **, and * denote significance at the level of $1 \%, 5 \%$, and $10 \%$, respectively. The bound tests was based on Pesaran et al. (2001) and the GH test on Gregory and Hansen (1996).

\subsection{Effect of Derivatives Market Development on Economic Growth and Volatility}

As the existence of co-integration with derivatives, business acceptance, along with economic growth and interest rate of China, in addition to progress volatility in India occurs, we examined its long run connection more. Equation was estimated by us (1) for China and also (2) for India that uses 2 long run estimations, FMOLS and DOLS, as well as provides the outcomes in Table 6. For starters, additionally to revealing the drastically beneficial impact over financial progress about rate of interest in the long term, above 2 options displayed good effect of the derivatives industry on financial development. Our outcomes offered promoting data for a great deal of empirical as well as theoretical scientific research over the effect of common improvement of economic markets to financial development in the long term (Ang 2008; Beck et al. 2000; Levine 2005; Levine et al. 2000).

4 The two types of unit-root tests rejected the null hypothesis that each variable contains unit roots in all countries when the variables were in terms of difference. To conserve space, the results are available upon request.

5 As the sample was relatively small, we use the critical values for the bound tests proposed by Narayan (2005). With 40 observations included in the estimation with an unrestricted intercept and unrestricted trend, the upper bound of the critical values were 5.64 and 3.76 at the significance level of $5 \%$ and $10 \%$, respectively. Our results also confirmed the cointegration relationship in China for the case of economic growth and in India for the case of economic volatility.

Particularly, our results seem to help backing the concept of Ariff as well as Baluch (2007), whom highlight the job of 
liquidity amount of derivatives market segments in aiding financial development. Additionally, Zhou (2016) analytically suggests the originating as well as improvement of China's derivative industry have committing consequences towards huge import of the country, quick financial progress, and slow capability of fiscal framework. Next, we discovered the destructive effect of the economic sector on Indian development volatility. The enormous rise in the improvement of derivatives market will show bad consequences in the end for India. The identical pattern was captured with business acceptance in India.

\begin{tabular}{|c|c|c|c|c|c|c|c|c|}
\hline \multirow[b]{4}{*}{ LEERR } & \multicolumn{4}{|c|}{ Deperndeni Y aniedie: LuCDPR } & \multicolumn{4}{|c|}{ Dypendant Veriable vol } \\
\hline & \multicolumn{4}{|c|}{ China } & \multicolumn{4}{|c|}{ fatia } \\
\hline & \multicolumn{2}{|c|}{ pors } & \multicolumn{2}{|c|}{ nots } & \multicolumn{2}{|c|}{ bots } & \multicolumn{2}{|c|}{ Exots } \\
\hline & 01290 & mosen & atos: & 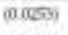 & $+6897 \div$ & 10050931 & - 0 s\$1 & 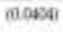 \\
\hline ZnOREN & - Q. & astaly & $+1 \mathrm{k}: \mathrm{x}^{+2}$ & $0,02 \pi$ & .1844 & (10.1813) & -1086 & expos \\
\hline INTR & ans: & 100004 & $0400 \%$ & pueso & ause & parain & oug & $\operatorname{mos} \theta$ \\
\hline Cantart & $1892 \div$ & $\max$ & 20176 & (1) & $\operatorname{sen}-$ & (20.002) & $2 x n=$ & $\operatorname{sen} 9$ \\
\hline
\end{tabular}

Notes: $* * *, * *, *$ denote significance at the level of $1 \%, 5 \%$, and $10 \%$, respectively. Standard deviation is in parentheses. The estimation includes a dummy for the structural break.

We then examined the short-run relationship among GDP growth, derivatives market advancement, trade openness, as well as the rate of interest. Due to the existence of cointegration, the adoption of VECM than compared to VAR had been a lot better. Thus, we practiced the earlier strategy concerning China and follow the second way of the various extra nations with Equation (5), with the variables in very opening impact. We captivated instinct reply works (IRFs) and displays the outcomes in Figure two. Graphical portrayals of the IRFs are able to clarify the powerful connection, as they clearly depicts the result of an adjustable to a shock to itself as well as to various other variables over time. Particularly, a reaction to GDP rise is certinly impacted by its shock, along the most well-known consequence encountered in China. A reaction to GDP rise offered by business acceptance was a lot more substantial in China as comapred to the various other 3 nations, as well as the result with the places in response to the rate of interest displayed a diverse pattern. Financial progress of China turned to be favorably affected by the derivatives market place during the very opening 12 months though this particular influence proved unfavorable about time, as well as the other 3 nations gave a good effect even though along a reasonable magnitude.

We clearly displayed IRFs needed for connection among other variables and development volatility in 3rd Figure . The IRFs had been depending over the situation's VECM of India as well as also the China's VAR, Japan, along with United States as a result of the outcomes from the cointegration assessments. Volatility shocks have been captured to be favorably impacted itself over China though the outcome steadily denied about time although volatility in Japan had an risingly collective influence by itself with the time. The derivatives sector's shocks had been discovered to have an optimistic impact on the progress volatility of Japan as well as India, though this particular

influence was continual overtime. The volatility at the progress rate of United States was impacted marginally by shocks of the derivatives industry although no influence was discovered for China's situation. With regards to the outcome of the shocks of business acceptance, just India encountered a damaging outcome connected with progress volatility as well as the 3 continuing lands had very little impression. The identical arrangement was noticed for China and there development volatility was associated to shocks in rates of interest.
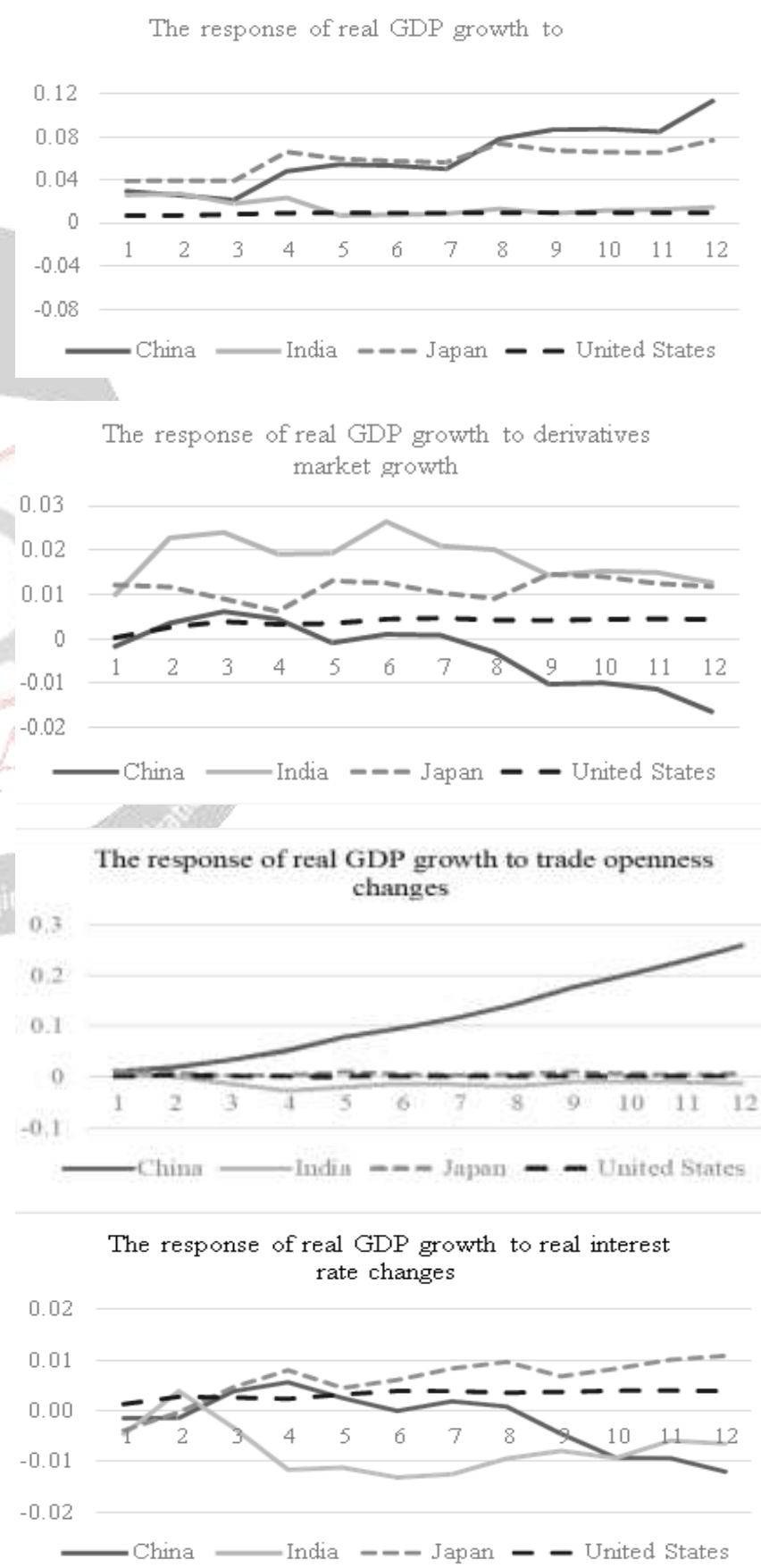

Figure 2. Cumulative orthogonalized impulse response function (the model includes GDP growth). 
The response of real growth volatility to

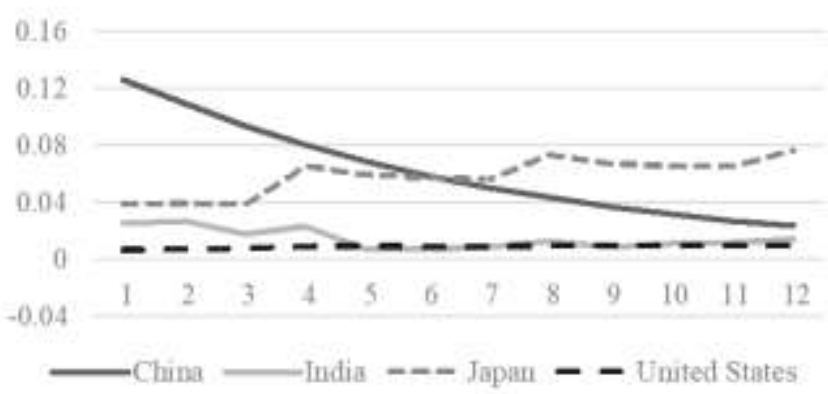

The response of real growth volatility to
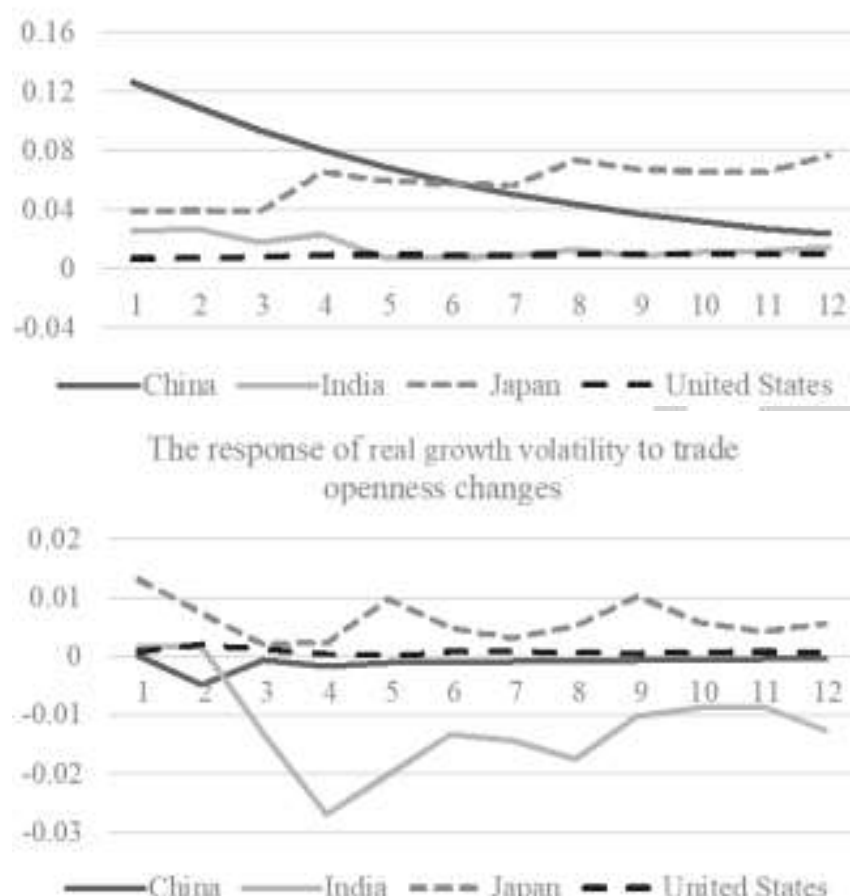
interest rate changes

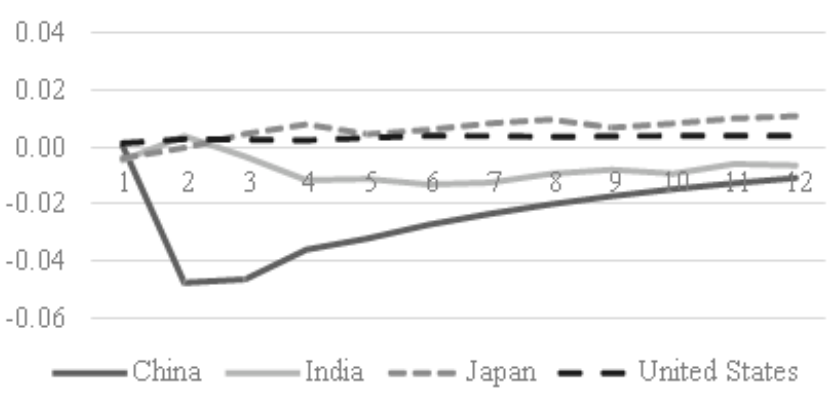

Figure 3. Cumulative orthogonalized impulse response function (the model include the volatility of GDP growth).

\subsection{Granger Causality Effect of Derivatives Market Development on Economic Growth and Volatility}

Last but not least, we carried out a Granger causality examination to disclose any kind of causal associations involving variables. Claimed in Table seven are actually the outcomes pertaining to the design which has economic development with a number of fascinating results. For starters, we discovered absolutely no formal association somewhere among financial progress as well as also the derivatives market place of Japan and China. Meanwhile, a single direction effect of financial progress on the derivatives sector was in India, as well as the opposite was noticed in the United States. Next, financial development was strongly linked with business acceptance, as a bidirectional formal association was in Japan as well as India, along with a single direction effect out of financial progress on business openness was observed in Japan. The association of it's with the rate of interest was much less substantial, along a single direction connection commonly formed solely in China as well as Japan. Third, when it arrived to a formal association among the derivatives marketplaces as well as the 2 continuing variables, India had the best energetic impulse, as the derivatives sector was discovered to posses a bidirectional association with the rate of interest along with a unidirectional influence on business acceptance. Japan left a unidirectional effect on the derivatives industry on both the rate of interest as well as business acceptance, while a unidirectional impacted was observed by business acceptance in the United States. The results of ours in relation to the causality connection had been rather distinct from the latest scientific analysis. Vo et al. (2019) clearly depicts the bidirectional Granger causality involving economic growth as well as derivatives marketplaces internationally utilizing the panel vector autoregressive (PVAR) technique, while $S$, endeniz-Yüncü et al. (2018) depicts the unidirectional causality in greater income places from financial progress to the improvement of a futures market, a tiny proportion of the common derivative industry.

Table 7. Causality tests (the model includes GDP growth).

\begin{tabular}{|c|c|c|c|c|}
\hline Nall Hypothesis & Chised & Indta & Japan & Uniked Shates \\
\hline 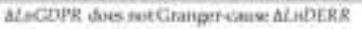 & 5.9 & $\operatorname{tazs}=$ & $30 \mathrm{x}$ & $2 \mathrm{u}$ \\
\hline 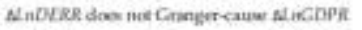 & 19 & $7 \%$ & 1.89 & $127+\cdots$ \\
\hline 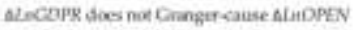 & 302 & $13.54 \ldots$ & $13.34 \ldots$ & $1352 \approx$ \\
\hline 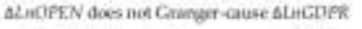 & 1.52 & $92=$ & $7.78 *$ & 3,09 \\
\hline 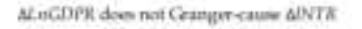 & 2.93 & $0.00 \mathrm{w}-$ & จ200* & 3.5 \\
\hline 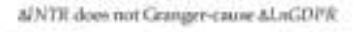 & 4.0 & t.9. & 1.92 & 6.13 \\
\hline 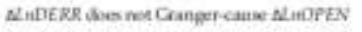 & $9 \%=$ & 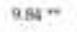 & $9 \pi \pi$ & 3,62 \\
\hline 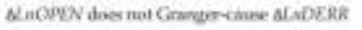 & 1 in & a. & IAt & a.s. \\
\hline 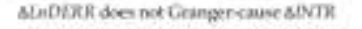 & $3 \omega$ & $40,54=$ & $106=$ & $a x$ \\
\hline 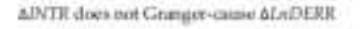 & 2.78 & $950 \mathrm{~m}$ & 1.16 & 2 tot \\
\hline 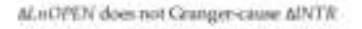 & 43 & $7 \mathbf{a}$. & 357 & 2.16 \\
\hline AINTR dus mit Granger-cause at.nOPEN & 3.16 & $4 \pi$ & 223 & $9 \pi=$ \\
\hline
\end{tabular}

Notes: $* * *, * *, *$ denotes significance at the level of $1 \%$, $5 \%$, and $10 \%$, respectively. The Wald test, which tests the joint significance of the lagged values of the independent variable is reported. The Wald test followed a chi-square distribution. Granger-causality results were based on a vector error correction model (VECM) for China and a vector autoregressive model (VAR) for India, Japan, and the United States. China, India, and Japan were regressed based on four lags, and the United States was based on three lags. 
$\Delta$ indicates the variable is in the first different form while Ln denotes the variable is in terms of logarithm.

Table 8 reports the fundamental association relating to the prototypical that depended on evolution volatility along with extra variables. In general, variables receive far more Granger causal backlinks to one another in India's situation instead of every other nation, specifically, China, Japan, and United States. Precisely, India had encountered the two directional Granger link for website with development volatility, derivatives sector, as well as the rate of interest. India also encountered the single directional Granger impact from the derivatives market to development volatility. This adverse prospective outcome analytically recommended a cautioning worry that the improvement of derivatives marketplaces might produce an anxiety to the private economic climate as elevated by (Sammer and Haiss 2010).The rate of interest in China was discovered to have a unidirectional impact on all business acceptance as well as development volatility. While United States had encountered the unidirectional effect of the derivatives industry as well as rate of interest over business openness. A unidirectional impact coming from the improvement in the derivatives market segments on interest rate was observed.

Table 8. Causality tests (the model include the volatility of GDP growth).

\begin{tabular}{|c|c|c|c|c|}
\hline Nuali Hyputbesis & China & hadia & Japan & United Sabes \\
\hline Aval does not Grangereause AfaDERK & 0 in & anow & 1.15 & ais \\
\hline 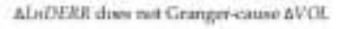 & 1.42 & 30.36 & Lin & 0.5 \\
\hline 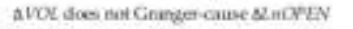 & 2.23 & 5.12 & 263 & 0.12 \\
\hline 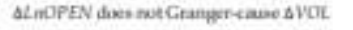 & 0.5 & 256 & 0.17 & oat \\
\hline AVOL dos nut Crangereave AINTR & 155 & $90.50=0$ & 0.80 & 802 \\
\hline ANTK doo mitChanger-aver AVOL. & $467 \%$ & $14.45+2$ & $0+2$ & a.so \\
\hline 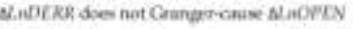 & 0.64 & $930 \%$ & 0.00 & $9 s \ldots$ \\
\hline 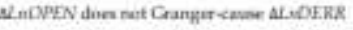 & IR & 1.12 & 0.55 & ain \\
\hline 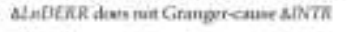 & 004 & $166.61 \mathrm{~m}$ & $326^{\circ}$ & 0.10 \\
\hline 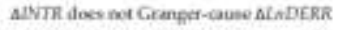 & 1.32 & $12.87-$ & $0 \infty$ & $0 \mathrm{~m}$ \\
\hline 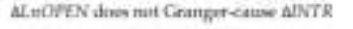 & asi & $22.30+1$ & 1.27 & $\infty \omega$ \\
\hline AINIT does bot Cirangercau $A$ InCVEN & $13,31=$ & $2 \pi$ & 0.21 & $3.77^{\circ}$ \\
\hline
\end{tabular}

Notes: $* * *, * *, *$ denote significance at the level of $1 \%, 5 \%$, and $10 \%$, respectively. The Wald test, which tests the joint significance of the lagged values of the independent variable is reported. The Wald test followed a chi-square distribution. Granger-causality results were based on the VAR model for China, Japan, and the United States using one lag, and India was based on the VECM with four lags. $\Delta$ indicates the variable is in the first different form while $L n$ denotes the variable is in terms of logarithm.

\section{Concluding Remarks}

The improvement of the derivatives market place has had a risingly critical job in the economic sector, helping not just as a highly adequate shuffling appliance but additionally as a helpful provider of instant information, therefore improving the effectiveness of economic market activities. The latest curiosity concentrates on the way the improvement of derivatives marketplaces influences the economic climate as an entire. Some investigation has hypothetically recommended that the derivatives sector favorably impacts financial progress by advancing chief buildup, producing expense more effective by providing much more variety in highly unsafe tasks and decreasing anxiety of the economic climate as being a potential risk hedging application. Nevertheless, inadequate empirical research has been carried out on this critical association.

We examine the association among financial progress, volatility, as well as the derivatives sector and various other macroeconomic variables: the interest and rate of trade openness. We chose the 4 leading economic countries (China, India, Japan, and the U.S.), and they have an older derivatives sector, for our evaluation through the time series econometric techniques on an updated dataset in place to 2017 final quarter. The software of time series methods can vary throughout lands due to the dynamics of the information. As a result, several seasoned, suitable, and strong econometric strategies are actually utilized in that analysis.

The China's derivative market place was discovered to possess a drastically detrimental influence on financial development in the temporary, but this particular effect turns good in the long haul. The 3 continuing nations (India, Japan, and the U.S.), the outcomes likewise expose no long run effect of the derivatives industry on financial progress, though a good effect was bought in the very short run. Furthermore, the causality check suggests that India has a single directional impact from the market of derivatives to fiscal development whereas the opposite arrangement is actually found to the U.S., along with absolutely no causality result was discovered among these 2 variables in Japan and China. Additionally, India had encountered the bidirectional causal connection India with progress volatility, the derivatives marketplaces, as well as the rate of interest.

We achieved that improvement of the derivatives markets had a beneficial impact on financial development in the very short run, as suggested in India, Japan, and the U.S., though it might steadily switch unfavorable, as in China. Nevertheless, it was discovered to create a surprise impact on development volatility in India. In lighting of the results, this particular analysis upholds the concept over the convenient consequence of the derivatives industry on financial development. As a result, we propose that just about any technique for improving or perhaps improving the dimensions of the derivatives sector must be promoted, particularly in appearing as well as developing countries and so as to increase economic growth, though it's crucial that you have a good regulatory framework to be able to stop unintended effects, like producing a destructive 
influence in the very short run as witnessed in China, creating the development volatility as noticed in India.

A constraint of the present papers would be that the sample sizes such as 4 selected lands covered around eighty observations and also the programs of VECM or VAR needed some time lags for those variables, major to a considerable contraction of the selection of the amounts of independence. Being a direct result, it brought up a problem in association to the partial coefficients in the estimation. From the succeeding scientific studies of ours, a far more extensive addition of powerful panel information versions, device root examinations, or maybe co-integration evaluation is going to be put on to make certain that empirical results tend to be more powerful.

\section{REFERENCES}

[1] Acemoglu, Daron, and Fabrizio Zilibotti. 1997. Was Prometheus unbound by chance? Risk, diversification, and growth. Journal of Political Economy 105: 709-51. [CrossRef]

[2] Allayannis, George, and Eli Ofek. 2001. Exchange rate exposure, hedging, and the use of foreign currency derivatives. Journal of International Money and Finance 20: 273-96. [CrossRef]

[3] Ang, James. B. 2008. A survey of recent developments in the literature of finance and growth. Journal of Economic Surveys 22: 536-76. [CrossRef]

[4] Ang, James B., and Warwick J. McKibbin. 2007. Financial liberalization, financial sector development and growth: Evidence from Malaysia. Journal of Development Economics 84: 215-33. [CrossRef]

[5] Atilgan, Yigit, K. Ozgur Demirtas, and Koray D. Simsek. 2016. Derivative markets in emerging economies: A survey. International Review of Economics and Finance 42: 88-102. [CrossRef]

[6] Bank for International Settlements (BIS). n.d. Available online: https://www.bis.org/statistics/ (accessed on 25 September 2018).

[7] Bartram, Söhnke M., Gregory W. Brown, and Frank R. Fehle. 2009. International evidence on financial derivatives usage. Financial Management 38: 185-206. [CrossRef]

[8] Beck, Thorsten, Ross Levine, and Norman Loayza. 2000. Finance and the sources of growth. Journal of Financial Economics 58: 261-300. [CrossRef]

[9] Baluch, A., and Mohamed Ariff. 2007. Derivative Markets and Economic Growth: Is There a Relationship?

[10] Working Paper Series 13/2007; Australia: Bond University, Globalization \& Development Centre, Available online: https://library.bond.edu.au/ (accessed on 10 September 2018).

[11] Bowdler, Christopher, and Adeel Malik. 2017. Openness and inflation volatility: Panel data evidence.

[12] North American Journal of Economics and Finance 41: 5769. [CrossRef]
[13] Chaiechi, Taha. 2012. Financial development shocks and contemporaneous feedback effect on key macroeconomic indicators: A post Keynesian time series analysis. Economic Modelling 29: 487-501. [CrossRef]

[14] Cos kun, Yener, Ünal Seven, H. Murat Ertug ־ul, and Talat Ulussever. 2017. Capital market and economic growth nexus: Evidence from Turkey. Central Bank Review 17: 19-29. [CrossRef]

[15] Elliott, Graham, Thomas J. Rothenberg, and James H. Stock. 1996. Efficient tests for an autoregressive unit root. Econometrica 64: 813-36. [CrossRef]

[16] Engle, Robert F., and Clive WJ Granger. 1987. Cointegration and error correction: Representation, estimation, and testing. Econometrica 55: 251-76. [CrossRef]

[17] Future Industry Association. n.d. Available online: https://fia.org/ (accessed on 25 September 2018).

[18] Gregory, Allan W., and Bruce E. Hansen. 1996. Residualbased tests for cointegration in models with regime shifts.

[19] Journal of Econometrics 70: 99-126. [CrossRef]

[20] Gries, Thomas, Manfred Kraft, and Daniel Meierrieks. 2009. Linkages between financial deepening, trade openness, and economic development: Causality evidence from SubSaharan Africa. World Development 37: 1849-60. [CrossRef]

[21] Haiss, Peter, and Bernhard Sammer. 2010. The Impact of Derivatives Markets on Financial Integration, Risk, and Economic Growth. Available online: http://dx.doi.org/10.2139/ssrn.1720586 (accessed on 4 October 2018). Hammoudeh, Shawkat, and Michael McAleer. 2013. Risk management and financial derivatives: An overview.

[22] North American Journal of Economics and Finance 25: 10915. [CrossRef]

[23] Huang, Bwo-Nung, Chin-Wei Yang, and John Wei-Shan Hu. 2000. Causality and cointegration of stock markets among the United States, Japan and the South China Growth Triangle. International Review of Financial Analysis 9: 28197. [CrossRef]

[24] Huang, Pinghsun, M. Humayun Kabir, and Yan Zhang. 2017. Does corporate derivative use reduce stock price exposure? Evidence from UK firms. Quarterly Review of Economics and Finance 65: 128-36. [CrossRef]

[25] Hull, John C. 2005. Options, Futures, and Other Derivatives. Upper Saddle River: Pearson Education.

[26] Khan, Habib Hussain, Ali M. Kutan, Iram Naz, and Fiza Qureshi. 2017. Efficiency, growth and market power in the banking industry: New approach to efficient structure hypothesis. North American Journal of Economics and Finance 42: 531-45. [CrossRef]

[27] Kim, Dong-Hyeon, Shu-Chin Lin, and Yu-Bo Suen. 2010. Dynamic effects of trade openness on financial development. Economic Modelling 27: 254-61. [CrossRef]

[28] King, Robert G., and Ross Levine. 1993. Finance and growth: Schumpeter might be right. The Quarterly Journal of Economics 108: 717-37. [CrossRef] 
[29] Krebs, Tom. 2003. Growth and welfare effects of business cycles in economies with idiosyncratic human capital risk. Review of Economic Dynamics 6: 846-68. [CrossRef]

[30] Levine, Ross. 2005. Finance and growth: Theory and evidence. Handbook of Economic Growth 1: 865-934.

[31] Levine, Ross, Norman Loayza, and Thorsten Beck. 2000. Financial intermediation and growth: Causality and causes. Journal of Monetary Economics 46: 31-77. [CrossRef]

[32] Lien, Donald, and Mei Zhang. 2008. A survey of emerging derivatives markets. Emerging Markets Finance and Trade

[33] 44: 39-69. [CrossRef]

[34] Menyah, Kojo, Saban Nazlioglu, and Yemane Wolde-Rufael. 2014. Financial development, trade openness and economic growth in African countries: New insights from a panel causality approach. Economic Modelling 37: 386-94. [CrossRef]

[35] Narayan, Paresh Kumar. 2005. The saving and investment nexus for China: Evidence from cointegration tests.

[36] Applied Economics 37: 1979-90. [CrossRef]

[37] Narayan, Paresh Kumar, and Russell Smyth. 2005. Electricity consumption, employment and real income in Australia evidence from multivariate Granger causality tests. Energy Policy 33: 1109-16. [CrossRef]

[38] Nguyen, Phuc Van, and Duc Hong Vo. 2019. Macroeconomics Determinants of Exchange Rate PassThrough: New Evidence from the Asia-Pacific Region. Emerging Markets Finance and Trade, 1-16. [CrossRef]

[39] Pesaran, M. Hashem, Yongcheol Shin, and Richard J. Smith. 2001. Bounds testing approaches to the analysis of level relationships. Journal of Applied Econometrics 16: 289-326. [CrossRef]

[40] Pradhan, Rudra P., Mak B. Arvin, John H. Hall, and Sahar Bahmani. 2014. Causal nexus between economic growth, banking sector development, stock market development, and other macroeconomic variables: The case of ASEAN countries. Review of Financial Economics 23: 155-73. [CrossRef]

[41] Rousseau, Peter L., and Paul Wachtel. 2002. Inflation thresholds and the finance-growth nexus. Journal of International Money and Finance 21: 777-93. [CrossRef]

[42] Ruiz, Jose L. 2018. Financial development, institutional investors, and economic growth. International Review of Economics and Finance 54: 218-24. [CrossRef]

[43] S, endeniz-Yüncü, I'lkay, Levent Akdeniz, and Kürs sat Aydog an. 2018. Do stock index futures affect economic

[44] growth? Evidence from 32 countries. Emerging Markets Finance and Trade 54: 410-29. [CrossRef]

[45] Sundaram, Rangarajan K. 2012. Derivatives in Financial Market Development. London: International Growth Centre, p. 39. Tanha, Hassan, and Michael Dempsey. 2017. Derivatives usage in emerging markets following the GFC:

[46] Evidence from the GCC countries. Emerging Markets Finance and Trade 53: 170-79. [CrossRef]

[47] Thumrongvit, Patara, Yoonbai Kim, and Chong Soo Pyun. 2013. Linking the missing market: The effect of bond markets on economic growth. International Review of Economics and Finance 27: 529-41. [CrossRef]

[48] Tsouma, Ekaterini. 2009. Stock returns and economic activity in mature and emerging markets. Quarterly Review of Economics and Finance 49: 668-85. [CrossRef]

[49] Vashishtha, Ashutosh, and Satish Kumar. 2010. Development of financial derivatives market in India-A case study. International Research Journal of Finance and Economics 37: 15-29.

[50] Vo, Duc Hong, Phuc Van Nguyen, Ha Minh Nguyen, Anh The Vo, and Thang Cong Nguyen. 2019. Derivatives market and economic growth nexus: Policy implication for emerging markets. North American Journal of Economics and Finance. [CrossRef]

[51] World Bank. n.d. Available online: https://data.worldbank.org/.

[52] Zhou, Tianying. 2016. Overview on derivatives trade in china. European Scientific Journal 12: 153-62. [CrossRef]

[53] Zivot, Eric, and Donald W. K. Andrews. 1992. Further evidence on the great crash, the oil price shock, and the unit root hypothesis. Journal of Business and Economic Statistics 10: $251-70$.

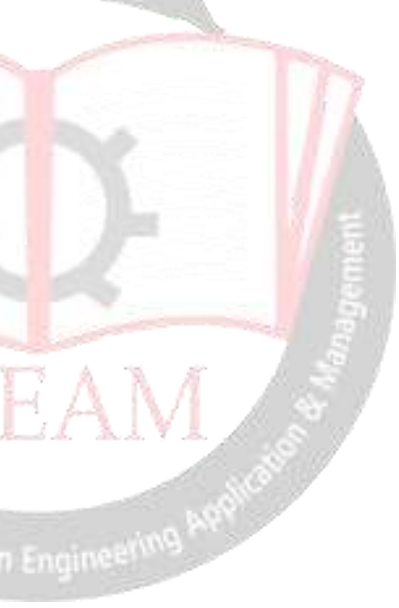

